\title{
Linfoma B intravascular: comprometimento bilateral da suprarrenal em paciente adulta jovem
}

\section{Intravascular large B cell lymphoma: impairment of bilateral adrenal in young woman}

Marília Sena de Felipe'; Chrystian Junqueira Alves²; Rogerio Estevam Farias ${ }^{3}$

unitermos

Linfoma não Hodgkin

Linfoma de células B

Linfoma difuso de grandes

células B

Linfoma histiocítico difuso

\section{resumo}

O linfoma B intravascular de grandes células (IVLBCL) é uma doença rara caracterizada pela proliferação neoplásica de células linfoides no interior de capilares. Relatamos um caso de IVLBCL em paciente jovem do sexo feminino com comprometimento bilateral da glândula suprarrenal. O exame imuno-histoquímico confirmou o IVLBCL. A afinidade entre órgãos endócrinos e células linfoides é uma hipótese levantada para explicar a correlação verificada entre o IVLBCL e o comprometimento da glândula suprarrenal. Além disso, a associação entre o IVLBCL e a sintomatologia descrita parece refletir um padrão que poderá auxiliar em um diagnóstico mais eficaz.

\section{abstract}

The Intravascular Large B-cell Lymphoma (IVLBCL) is a rare disease characterized by neoplastic proliferation of lymphoid cells within capillaries. We report a case of IVLBCL in a young female patient with bilateral involvement of the adrenal gland. Immunohistochemical examination confirmed IVLBCL. The relationship between endocrine organs and lymphoid cells is a hypothesis to explain the correlation observed between IVLBCL and the involvement of the adrenal gland. Moreover, the association between IVLBCL and the described symptomatology seems to reflect a pattern that may assist in a more effective diagnosis. key words

Non-Hodgkin lymphoma

B-cell lymphoma

Diffuse large B-cell

Iymphoma

Diffuse histiocytic

Iymphoma

1. Patologista do Hospital Nove de Julho. Instituto Oncológico. Laboratório de Patologia Eblen.

2. Bacharel em Ciências Biológicas. Laboratório de Imunologia. Instituto de Ciências Biológicas. Universidade Federal de Juiz de Fora (UFFF-MG).

3. Patologista; professor adjunto II do Departamento de Morfologia da UFIF-MG. 


\section{Introdução}

O linfoma $B$ intravascular de grandes células (IVLBCL) foi originalmente descrito como angioendotheliomatosis proliferans systematisata em 1959(11). Desde então, diversos casos foram reportados, sobretudo em relatos e em séries curtas $^{(12)}$. O IVLBCL é um raro subtipo de linfoma $B$ de grandes células (DBL) e é caracterizado por proliferação neoplásica de células linfoides no interior de capilares, pequenas veias e artérias; de forma que não existem células linfoides circulantes ou massa linfoide extravascular ${ }^{(8)}$. A grande maioria dos tumores é proveniente de linhagens de células $B$, e somente uma pequena porcentagem é proveniente de linhagens de células $\mathrm{T}^{(3,16)}$. O IVLBCL pode estar presente numa ampla faixa etária, mas é mais frequente em pacientes na sétima década de vida, afetando principalmente mulheres ${ }^{(1,15)}$. O diagnóstico pode ser dificultado pela tendência de a doença apresentar sintomatologia altamente variável e não específica ${ }^{(18)}$. $\mathrm{O}$ aumento bilateral da glândula suprarrenal e a febre de origem desconhecida têm sido notados como manifestação clínica em diversos $\operatorname{casos}^{(6,14)}$ e comumente associados à insuficiência da mes$\mathrm{ma}^{(4)}$. Apesar de o envolvimento de órgãos endócrinos ser raro em comparação com o sistema nervoso central (SNC) e a pele, órgãos mais frequentemente envolvidos, ao menos inicialmente ${ }^{(11,18)}$, Murase et al.(2) (2007) mostraram que aproximadamente $5 \%$ dos pacientes diagnosticados in vivo com IVLBCL apresentavam comprometimento primário de órgãos endócrinos, sendo que $2,5 \%$ dos casos apresentavam envolvimento da suprarrenal(12). No entanto, a grande maioria dos pacientes apresenta envolvimento sistêmico na autópsia ${ }^{(11)}$. Neste relato de caso, reportamos um raro caso de IVLBCL em paciente jovem do sexo feminino com comprometimento bilateral da glândula suprarrenal, apresentando marcações negativas para vírus da hepatite B (HBV) e herpes-vírus humano (HHV) $)^{(1)}$.

\section{Relato do caso}

Paciente do sexo feminino foi atendida em fevereiro de 2009, queixando-se de febre vespertina intermitente de origem súbita há aproximadamente dois meses e dispneia de esforço. Na mesma ocasião, foi diagnosticado um tumor bilateral na glândula suprarrenal, e os exames laboratoriais constataram anemia e leucocitose.

Foi realizada uma cirurgia na qual se retirou um tumor em topografia suprarrenal e o baço concomitantemente (esplenectomia total). Após um mês, a paciente foi atendida em caráter de urgência apresentando quadro de dispneia de repouso, vômitos incoercíveis, icterícia, desidratação e distensão abdominal acompanhada de dor abdominal difusa. O quadro clínico foi diagnosticado como septicemia não especificada, e a paciente foi a óbito alguns dias depois.

\section{Achados laboratoriais}

\section{Pré-cirúrgico}

O exame de sangue no pré-cirúrgico revelou anemia progressiva com hemoglobina de $4,5 \mathrm{~g} / \mathrm{dl}$ a $7,5 \mathrm{~g} / \mathrm{dl}$, hemácias de $3,4 \times 106 / \mathrm{ml}$, hematócrito de $16 \%$ a $25,6 \%$, leucocitose de $12.600 / \mathrm{ml} \mathrm{a} 15.400 / \mathrm{ml}$ e plaquetas de 571 $\mathrm{mil} / \mathrm{ml}$; a análise sanguínea também confirmou a presença de bastões, segmentados e linfócitos. A radiografia de tórax apresentou-se normal.

\section{Pós-cirúrgico}

Os achados laboratoriais após a cirurgia mostraram quadro de anemia severa progressiva, com hemoglobina de $4 \mathrm{~g} / \mathrm{dl}$ e hematócrito de $13 \%$, leucocitose importante de $38 \mathrm{mil} / \mathrm{ml}$ e achados de metamielócitos e segmentados no sangue periférico. Outros testes laboratoriais incluíram glicose de $164 \mathrm{mg} / \mathrm{dl}$, ureia de $106 \mathrm{mg} / \mathrm{dl}$, creatinina de 2,3 mg/dl, sódio de $154 \mathrm{mEq} / \mathrm{l} / \mathrm{dia}$, potássio de 5,8 $\mathrm{mEq} / \mathrm{l} /$ dia e cálcio de $2,4 \mathrm{mg} / \mathrm{dl}$.

\section{Resultados da patologia e imuno-histoquímica}

O exame anatomopatológico foi realizado logo após a retirada dos órgãos. O baço revelou aspecto normal, pesando $365 \mathrm{~g}$; apresentou a superfície externa amarronzada, aspecto vinhoso de consistência amolecida sem particularidades. O parênquima estava com arquitetura preservada e sem malignidade. $\mathrm{O}$ omento também apresentou o tecido adiposo livre de neoplasia.

As glândulas suprarrenais esquerda e direita mostravam tumorações, apresentando a superfície externa de cor castanho-amarelada, com áreas hemorrágicas e aspecto 
lobulado. Aos cortes, puderam-se observar tumorações vermelho-vinhosas, multinodulares de consistência firme e elástica, com maior eixo de $6,6 \mathrm{~cm}$, comprometendo os bordos laterais da peça cirúrgica.

Microscopicamente, os achados mais importantes evidenciados pela coloração com hematoxilina e eosina (HE) (Figura 1) foram os linfócitos grandes e atípicos com a relação núcleo/citoplasma alterada, de padrão intravascular e diversas áreas necróticas. Pôde-se observar frequentemente a obstrução parcial ou completa dos capilares.

O estudo imuno-histoquímico das células tumorais foi positivo para anticorpo anti-CD20 (Figura 2), indicando uma origem linfoide de células $B$. Anticorpos contra CD34 (Figura 3) revelaram marcação positiva, padrão vascular, demonstrando presença de células neoplásicas no interior dos vasos sanguíneos e além de células epiteliais remanescentes da suprarrenal (CD56+). Alguns focos de marcação anti-CD3 foram observados, indicando presença de linfócitos $T$ reativos no espaço perivascular. Imunomarcações para o vírus Epstein-Barr (EBV) e HHV do tipo 8 (HHV8) foram negativas.

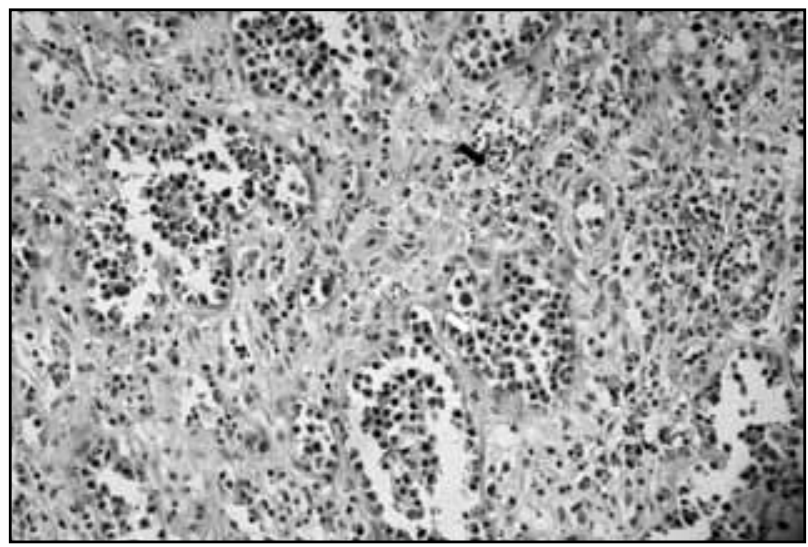

Figura 1 - Células linfoides no interior de vasos sanguíneos da glândula suprarrenal. A seta preta indica áreas de hemorragia, a seta branca indica a presença de linfócitos no interior dos vasos. Hematoxilina-eosina. Aumento de 100X

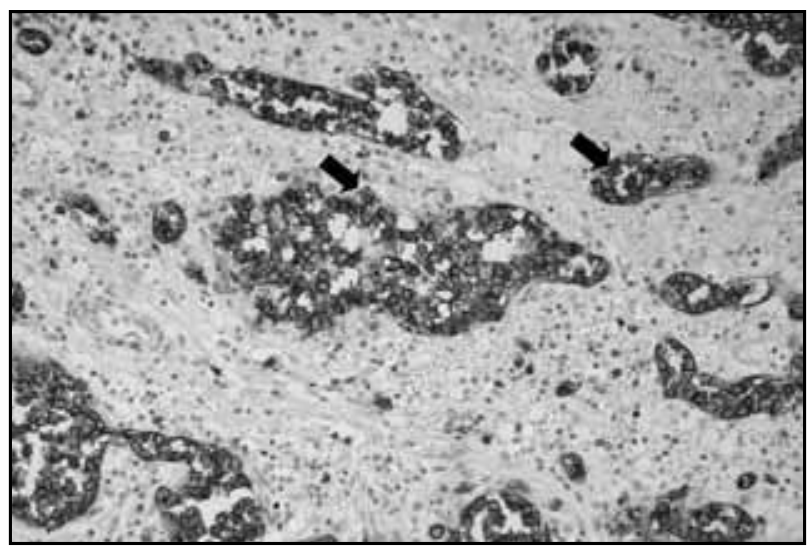

Figura 2 - Coleção de células linfoides $B$ marcadas com anticorpo anti $C D 20$ no interio de capilares da glândula suprarrenal. A seta indica alguns dos linfócitos aderidos ao endotélio. Aumento de 200X

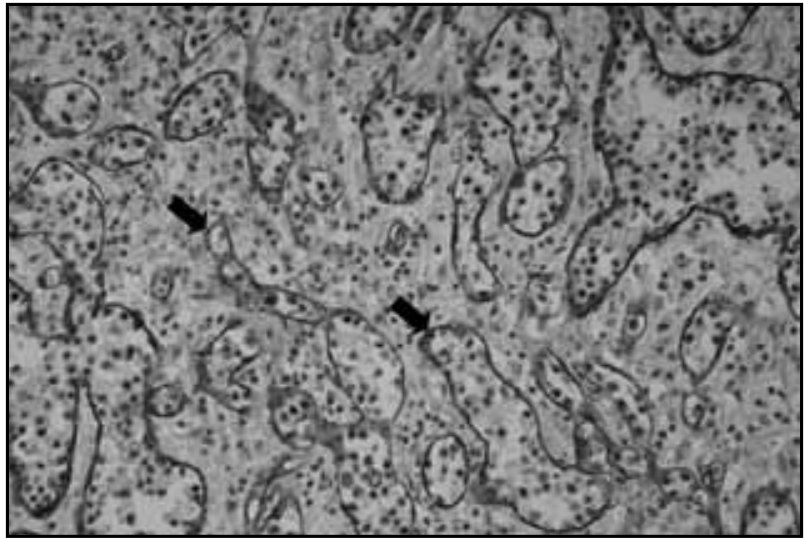

Figura 3 - Marcação com anticorpo anti CD34. As setas pretas indicam as células endoteliais dos capilares da glândula suprarrenal marcadas. No interior dos vasos, verifica-se a presença de células linfoides B neoplásicas. Aumento de 200X

\section{Discussão}

O IVLBCL caracteriza-se por neoplasia rara e agressiva, com alto índice proliferativo e tendência de permanecer no interior dos espaços vasculares, sem ocorrer infiltração no tecido adjacente ${ }^{(11)}$. Reconhece-se atualmente que o sistema nervoso e a pele são os órgãos mais frequentemente envolvidos com a doença, ao menos inicialmente ${ }^{(5,18)}$. Em estágios posteriores, o IVLBCL pode se disseminar para coração, pâncreas, fígado, baço, rins e até medula óssea. Raramente ocorre coagulação intravascular disseminada ${ }^{(8)}$. Embora o envolvimento de órgãos endócrinos possa ser uma manifestação menos frequente, existem descrições de pacientes que apresentam hipotireoidismo, hipopituitarismo e aumento da glândula suprarrenal em virtude do IVLBCL ${ }^{(9)}$. Svajdler et al. descreveram paciente com envolvimento bilateral das glândulas suprarrenal e hipófise, sugerindo a raridade desse perfil endócrino ${ }^{(18)}$. A despeito dessa constatação, Shanks et al. reportaram caso de envolvimento combinado entre glândulas tireoide e hipófise ${ }^{(16)}$ e Ohsawa et al. (1996) reportaram padrões histológicos de IVLBCL como os mais comuns entre 20 pacientes com linfomas de suprarrenal(13). Nosso relato se enquadra nesses padrões e propõe discussão a respeito de possível afinidade entre células linfoides atípicas e endotélio associado a órgãos endócrinos. Tem sido hipotetizado atualmente que o padrão intravascular do linfoma se deve a defeito no homing, envolvendo os receptores nas células linfoides: a perda das moléculas de adesão CD29 (beta-1 integrina) e CD54 (ICAM-1) ou a expressão de CD11a e CD49a nessas mesmas células e a expressão de ligantes correspondentes ao CD54 e CD106 nas células endoteliais ${ }^{(10,20)}$.

Uma característica que deve ser enfatizada neste relato é a ocorrência do IVLBCL em paciente do sexo feminino 
jovem. Normalmente, a doença se manifesta em pacientes idosas, não sendo rara, no entanto, a apresentação em pacientes de meia idade ${ }^{(3,16,20)}$. Outro aspecto da doença é o seu diagnóstico, bastante complexo de ser realizado em pacientes ante-mortem, em virtude da sintomatologia altamente variável e tardia. Nosso relato reportou o caso de uma paciente que apresentou inicialmente febre de origem desconhecida e fadiga, acompanhadas de anemia progressiva e leucocitose. Juntamente com essa sintomatologia foi verificado aumento bilateral das glândulas suprarrenais. No pós-cirúrgico a paciente apresentou progressão dos sintomas e complicações derivadas de septicemia não especificada que culminaram em óbito. Apesar de não ter sido investigado o envolvimento da hipófise neste relato, Svajdler et al. sugerem que o envolvimento de órgãos endócrinos, a febre de origem desconhecida e a fadiga acompanhados de outros possíveis sintomas não específicos devem ser uma pista para o estabelecimento de um diagnóstico mais precoce de IVLBCL ${ }^{(18)}$. Possivelmente, no momento em que foi realizada a cirurgia, a doença já estava em fase bastante avançada. No que se refere à insuficiência da suprarrenal, essa não foi constatada clinicamente, de forma que somente testes laboratoriais seriam capazes de realizar tal detecção ${ }^{(19)}$. A patogênese da insuficiência da suprarrenal no IVLBCL ocorreria devido à oclusão de pequenos vasos e capilares por células linfoides, levando a isquemia ou infarto da glândula. Além disso, a massa tumoral pode comprimir as células do parênquima, resultando em atrofia celular e disfunção do órgão(2).

Com relação às marcações para o EBV e para o HHV8, Ferry et al. descreveram caso de IVLBCL em paciente HIV+, mostrando que o espectro de associação entre HHV8 e doenças linfoides pode ser maior do que se pensava ${ }^{(7)}$. Yamada et al. também relataram um caso em que paciente portadora de IVLBCL e mioma uterino, aparentemente sem imunossupressão, apresentou positividade para EBV, a despeito de estudos anteriores, associando imunossupressão e EBV+ ${ }^{(17,21)}$. Com relação à paciente do presente estudo, aparentemente não imunossuprimida, verificamos a negatividade tanto para HHV8 quanto para EBV. Com vistas a esses dados, sugerimos a hipótese de um amplo espectro de associação entre tais patógenos e as doenças linfoproliferativas.

Em conclusão, descrevemos neste relato o caso de uma paciente jovem do sexo feminino apresentando sintomas iniciais de febre vespertina de origem súbita e dispneia de esforço, evidenciando ainda comprometimento bilateral da glândula suprarrenal. O exame imuno-histoquímico confirmou o IVLBCL negativo para EBV e HHV8. Tal estudo contribui para o fortalecimento da hipótese de afinidade entre células linfoides e órgãos endócrinos em alguns casos e sugere um padrão de sintomas associados como pista para um diagnóstico mais eficaz.

\section{Referências}

1. ASKARIAN, F.; XU, D. Adrenal enlargement and insufficiency: a common presentation of intravascular large B-cell lymphoma. Am J Hem, v. 81, p. 411-3, 2006.

2. CHU, P., COSTA, J., LACHMAN, M.F. Angiotropic large cell lymphoma presenting as primary adrenal insufficiency. Hum Pathol, v. 27, n. 2, p. 209-11, 1996.

3. DEMIRER, T.; DAIL, D. H.; ABOULAFIA, D. M. Four varied cases of intravascular lymphomatosis and literature review. Cancer, v. 73, p. 1738-45, 1994.

4. ELLIS, R. D.; READ, D. Bilateral adrenal non-Hodgkin's lymphoma with adrenal insufficiency. Postgrad Med J, v. 76, p. 508-9, 2000.

5. FERRERI, A. J. et al. Intravascular lymphoma: clinical presentation, natural history, management and prognostic factors in a series of 38 cases, with special emphasis on the "cutaneous variant." Br J Haematol, v. 127, n. 2, p. 173-83, 2004.

6. FERRY, J. A. et al. Intravascular lymphomatosis (malignant angioendotheliomathosis): a B-cell neoplasm expressing surface homing receptors. Mod Pathol, v. 1, p. 444-52, 1988.
7. FERRY, J. A. et al. HHV8-positive, EBV-positive Hodgkin lymphoma-like large B-cell lymphoma and HHV8positive intravascular large B-cell lymphoma. Mod Pathol, v. 22, n. 5, p. 618-26, 2009.

8. GATTER, K. C. W. R. Intravascular large B-cell lymphoma. In: JAFFE, E. S. et al. Pathology and genetics of tumours of haematopoietic and lymphoid tissues. World Health organization classification of tumours. Lyon, France: IARC Press, 2001. p. 177-8.

9. GLASS, J.; HOCHBERG, F. H.; MILLER, D. C. Intravascular lymphomatosis. A systemic disease with neurologic manifestations. Cancer, v. 71, p. 3156-64, 1993.

10. JAFFE, E. S. et al. Pathology and genetics of tumours of haematopoietic and lymphoid tissues. World Health Organization Classification of Tumours. Lyon: IARC Press, 2001.

11. LAPKUVIENE, O.; FORCHETTI, D.; ROEPKE, J. E. Unusual sites of involvement by hematologic malignancies: case 1 . Intravascular large B-cell lymphoma presenting with CNS symptoms. J Clin Oncol, v. 19, n. 19, p. 3988-91, 2001.

12. MURASE, T. et al. Intravascular large B-cell lymphoma (IVLBCL): a clinicopathologic study of 96 cases 
with special reference to the immunophenotypic heterogeneity of CD5. Blood, v. 109, n. 2, p. 478-85, 2007.

13. OHSAWA, M. et al. Malignant Iymphoma of the adrenal gland: Its possible correlation with the Epstein-Barr virus. Mod Pathol, v. 9, p. 534-43, 1996.

14. PRAYSON, R. A. et al. Angiotropic large-cell lymphoma in a patient with adrenal insufficiency. Arch Pathol Lab Med, v. 115, p. 1039-41, 1991.

15. SANNA, P. et al. Angiothropic (intravascular) large cell lymphoma: case report and short discussion of the literature. Tumori, v. 83, p. 772-5, 1997.

16. SHANKS, J.H. et al. Angiotropic lymphoma with endocrine involvement. Histopathology, v. 31, p. 161-6, 1997.

17. SHIBATA, D.; WEISS, L. M.; HERNANDEZ, A. M. EpsteinBarr virus-associated non-Hodgkin's lymphoma in patients infected with the human immunodeficiency virus. Blood, v. 81, p. 1202-9, 1993.

18. SVAJDLER, M. et al. Intravascular variant of diffuse large B-cell lymphoma with combined endocrine involvement. Wien Klin Wochenschr, v. 118, p. 422-5, 2006.

19. UDELSMAN, R. D. H. An 82-year-old woman with bilateral adrenal masses and low-grade fever. N Engl J Med, v. 343, n. 20, p. 1477-83, 2000.

20. WOLTER, M. et al. Intravascular large cell lymphoma revealed by diffuse teleangiectasia and cauda equina syndrome. Ann Dermatol Venereol, v. 129, p. 320-4, 2002.

21. YAMADA, N. et al. CD5+ Epstein-Barr virus-positive intravascular large B-cell lymphoma in the uterus coexisting with huge myoma. Am J Hematol, v. 78, n. 3, p. 221-4, 2005. 